\title{
HAVING A PERMANENT RESIDENT IN INTENSIVE CARE: THE REWARDS AND CHALLENGES
}

\section{AUTHORS:}

1. Sharon M Wetzig: RN, BN, GC (Critical Care), MEd. (FET); Clinical Nurse Consultant, Intensive Care, Princess Alexandra Hospital

2. Catherine Walsh: BSocWk; Social Worker, Intensive Care and Trauma, Princess Alexandra Hospital

3. Cecile Prescott: BOccThy (Hons1), BA (Psych); Senior Occupational Therapist, Intensive Care and Trauma, Princess Alexandra Hospital

4. Peter S Kruger: MBBS, FANZCA, FJFICM; Deputy Director, Intensive Care, Princess Alexandra Hospital

5. Danielle Griffiths: RN, BN, GC (Intensive Care); Clinical Nurse

6. Fiona Jennings: RN, BN, GC (Critical Care); Acting Clinical Nurse Consultant, Intensive Care, Princess Alexandra Hospital

7. Leanne M Aitken: RN, PhD; Chair of Critical Care Nursing Intensive Care, Princess Alexandra Hospital and Research Centre for Clinical \& Community Practice Innovation, Griffith University 
Authors' Address:

Intensive Care Unit (Ward 3A)

Princess Alexandra Hospital

Ipswich Road

Wooloongabba QLD 4102

Phone: 0732402393

Fax: 0732407074

Email: Sharon Wetzig@health.gld.gov.au

\section{KEY WORDS:}

Critical care, long-term patient, mechanical ventilation, quadriplegia, locked-in, rehabilitation 


\section{ABSTRACT:}

Background: Intensive care units are generally structured and staffed to care for short term critically ill patients. This is in contrast to the increasing incidence of patients who require long term (i.e. greater than six months) intensive care in the contemporary health care context.

Aim: The aim of this paper is to share our experience of caring for a long term ventilated patient in intensive care, including providing a summary of strategies and considerations that proved effective in our setting.

Process: Dealing with the initial reactions of the staff, patient and family was the first focus of care, with strategies developed to manage the psychological as well as practical challenges. Core to subsequent strategies was the early formation of a multi-disciplinary case management team. Ongoing challenges included integrating rehabilitation care into the intensive care, developing effective multi-dimensional communication strategies, facilitating appropriate involvement of the patient and her family, operationalising trips outside the intensive care environment and adapting the model of nursing care to suit the context.

Conclusion: Elements essential for the effective care of a long term patient within the intensive care setting included the development and maintenance of an open and honest relationship with the patient and family, regular multidisciplinary case management meetings and effective communication strategies throughout the health care team. Importantly, clinical leaders should remain open to considering new ideas and strategies that facilitate effective care for a patient whose primary focus is different to the majority of intensive care patients. 


\section{INTRODUCTION}

You would not normally expect to find a 'permanent resident' in a large, tertiary referral Intensive Care Unit (ICU) with an average length of stay of five days. ${ }^{1}$ However this is exactly the situation in which we currently find ourselves. Although largely unreported in contemporary literature, it is a situation that has become increasingly common in today's health care context as institutions struggle with the most appropriate area to care for permanently ventilator-dependent patients. ${ }^{2}$

The increasing frequency of patients requiring prolonged mechanical ventilation, often referred to as the chronically critically ill, has been noted and led to a two-day consensus conference in $2005 .{ }^{3}$ Although there are differences of opinion as to what constitutes a long-term ICU patient, or alternatively how prolonged mechanical ventilation (PMV) is defined, participants at this consensus conference agreed that PMV should be defined as $\geq 21$ consecutive days of mechanical ventilation for $\geq$ six hours per day. ${ }^{3}$ This broad categorisation results in a wide variety of challenges experienced by patients, with those who require mechanical ventilation on a permanent basis experiencing different challenges to those who are ventilated for several months.

The limited body of literature that describes the challenges associated with caring for PMV patients concentrates on the large sub-group of patients for whom weaning from ventilation represents a realistic option. ${ }^{4,5,6}$ Alternatively, Rudy et al ${ }^{6}$ investigated the benefits of providing care for the chronically 
critically ill in a low technology environment referred to as a special care unit (SCU) compared with an ICU. Patient outcomes including length of stay, mortality and complications were similar between the two care environments, with markedly reduced costs expended in the SCU. ${ }^{6}$ Although not explicitly stated, it appears that the sample in this study did not include patients who required lifelong ventilation, but were planning to return to the home environment.

Other literature reporting on the care the small sub-group of patients for whom ongoing mechanical ventilation and associated care is required has been limited to case studies. ${ }^{7}$ Importantly, no studies could be located that have explored the most effective method to care for patients in whom the plan is to transition care to the home environment.

Given the lack of available literature in this area, as well as the lack of local experience in caring for similar patients, when Sandra was admitted to our ICU with Locked-in Syndrome (LIS) we did not foresee the impact this situation would have (refer to Insert 1 for clinical details). Developing a model of care to encompass long term rehabilitation and transition to a home-care environment was not only unfamiliar for most of the team, but as we discovered highly complex. ${ }^{8}$

Having Sandra as a 'permanent resident' in ICU has been both challenging and rewarding. It has provided opportunity for creativity and innovation. We have been motivated to share this experience in an effort to provide support 
and guidance for other health care professionals. Various aspects of our experience are described together with a summary of important considerations for those in similar circumstances.

\section{INITIAL REACTIONS}

To begin with the ICU team had to deal with the enormity of the situation. We had a young woman, the mother of a young child, facing life-long ventilation. Those involved in her care were faced with the impact of Sandra's clinical condition, as well as her and her family's reactions to this. Responses from staff, though varied, demonstrated that Sandra's situation significantly affected people on an emotional level.

The concept of 'shattered assumptions', which describes the psychological impact of trauma in challenging fundamental beliefs or expectations, provides a way of understanding our initial reactions. ${ }^{9}$ For example, Sandra's situation challenged the widely held, though often subconscious, assumption that 'bad things shouldn't happen to good people'.

Once her clinical condition stabilised, the ICU team focused on ascertaining the most appropriate place for Sandra to be cared for within the hospital. We felt that the ICU setting was not a suitable place for a long-term patient, nor was it a environment conducive for rehabilitation. Normally, rehabilitation and discharge planning for a patient with such complex needs (particularly home ventilation) would be undertaken by other units within the hospital with the 
necessary expertise and experience. However, these services had become overwhelmed with patients sustaining traumatic high spinal cord injury and had exhausted capacity to provide assistance to other types of patients requiring high level home care. Over a period of around three months, which involved many multidisciplinary and inter-departmental discussions, it became clear that the ICU was the only feasible environment to deliver the continued care that Sandra required. The realisation that Sandra would become a 'permanent resident' in ICU brought further emotional upheaval within the team. Once again, our preconceived assumptions had been 'shattered'. In this case the belief that 'all patients in ICU are short-term and critically ill'. 9

Considerable time was spent developing proposals for additional support to meet Sandra's needs, and formulating funding applications on her behalf often to no avail. These challenges affected the team personally and professionally, impacting on the service offered and causing individuals to question their abilities at times. It meant that the staff involved worked many hours of personal time in coordinating and providing Sandra's care, to ensure that our overall service delivery did not suffer. Several staff members became disillusioned and frustrated with the system. Some team members had to withdraw from direct involvement to preserve their emotional health and to avoid a negative impact on Sandra's own coping mechanisms.

Of the strategies developed in response to these challenges, perhaps one of the most effective was the formalisation of a multi-disciplinary 'case management' team. This group included representatives from the senior 
nursing and medical staff, as well as staff from social work, speech pathology, physiotherapy and occupational therapy disciplines. The ability to talk about frustrations, as well as share successes, was of great benefit to all those involved. Regular meetings also promoted a stronger working relationship between members of the team. As a group we were able to develop some innovative strategies for providing optimal care as well as supporting each other. The constant presence of Sandra's family and their willingness to be active participants in the process provided added motivation to continue moving forward.

\section{INTEGRATING REHABILITATION CARE INTO ICU}

\section{$\underline{\text { Challenges }}$}

The evidence suggests that patients with LIS benefit from early intensive rehabilitation care. ${ }^{8}$ However many challenges were faced in respect to this in Sandra's case. These were largely related to her being located in the middle of a busy ICU setting. The difficulty of establishing an environment conducive to rehabilitation, as outlined by Casanova et $\mathrm{al}^{8}$ was evident. A routine was difficult to maintain and planned activities often had to be rescheduled. This was largely due to nursing and support staff needing to re-prioritise tasks to attend to the needs of acutely ill patients within the ICU. Initially, there were long periods of unproductive time, which resulted in Sandra spending her time either watching television or watching the unfolding dramas (and sometimes demise) of patients in adjacent bed areas - neither of which were considered constructive. 
The knowledge and experience of allied health team members was invaluable when it came to the task of developing Sandra's rehabilitation plan and undertaking the tasks involved. Although only resourced to provide care to acute ICU patients, they willingly obtained the required knowledge and gave additional time to ensure she received optimal rehabilitation care.

Due to her location in an acute ICU rather than a dedicated rehabilitation unit Sandra and her family were unable to participate in group therapy sessions. Such sessions provide important education and peer support for patients, while also allowing allied health staff to provide therapy to numerous patients at one time.${ }^{10}$ As a result, all of Sandra's therapy and discharge planning was completed on a 1:1 basis. Additionally, the services normally available in rehabilitation areas such as day-rooms, gymnasium, trial equipment and internet access could not be offered in ICU. All physical, speech and occupational therapy had to be performed in the ICU bed area which is not set up to accommodate the required resources. ${ }^{11}$

Access to equipment proved to be a considerable challenge as ICU does not keep the type of rehabilitation equipment that was required (i.e. wheelchair with head \& neck support, tilt-in-space shower chair, portable long-term ventilator). This meant that many items had to be borrowed, requiring ongoing negotiation with other hospital departments and corporate representatives.

We also learned that purchasing equipment for use in a rehabilitation environment requires consideration of a different range of issues than when 
equipment is purchased for use in ICU. In Sandra's case, we needed to consider the portability of equipment, size and weight, battery life and charging options. Additionally, purchasing of the necessary specialised equipment required some lateral thinking with regard to funding arrangements.

\section{$\underline{\text { Response }}$}

Our response to these challenges was largely aimed at developing the mindset of staff and making use of available resources and standard practices within the hospital. In order to encourage staff to view Sandra as rehabilitation patient rather than an acute ICU patient, we minimised her monitoring and medical reviews, and changed her charting from the ICU computerised system to standard hospital paper format. We communicated the reason for these changes to all staff and encouraged them to start considering Sandra a little differently to most other ICU patients (e.g. they could leave the room for short periods if a family member was present, Sandra should be considered competent to make her own decisions and is able to leave the ICU for outings).

We also moved Sandra into one of the previously unused isolation rooms which improved privacy for her and her family. The room was set up to look less like a hospital room and accommodate some home-style furnishings (refer to Figure 1). She also started wearing clothes (rather than a nightgown) during the day and going on outings. 
In addition to these strategies, we began to institute some practices that are normally part of a rehabilitation care model. ${ }^{8}$ For example; we scheduled a regular multidisciplinary case conference, the outcomes of which were documented in the patient progress notes. It assisted in providing continuity of care for staff caring for Sandra and in clarifying the various roles within the team. Literature focusing on rehabilitation in patients with long-term critical illness emphasise the importance of such a team approach in promoting optimal care. $^{11}$

The case management team was coordinated by the ICU Clinical Nurse Consultant who was able to provide a link between nursing, medical and allied health staff. Additionally, one ICU Staff Specialist was allocated to coordinate Sandra's medical care (usually they work on a rotating basis, caring for patients for a week at a time). Having one senior nursing and medical person responsible for her care was of great benefit in ensuring consistency and continuity of care for Sandra and her family. It also provided the opportunity for development of a strong rapport between Sandra, her family and the health-care team which was particularly beneficial when needing to discuss difficult issues. The importance of developing such a relationship is supported in current literature focusing on patient-centred care in ICU. ${ }^{12,13}$

Access to some hospital services that are not routinely used in ICU was also achieved. This included referral to a Leisure Therapist (who provided Sandra with a variety of activities and suggestions), pet therapy and meditation classes. While the effectiveness of such interventions has proven difficult to 
measure they are generally well received by patients and families in critical care. One possible reason for this is that they provide the 'simple pleasures' that patients desire yet are often denied them due to their illness. ${ }^{14,15}$ A number of alternative therapies (see Table 1) were also part of her care. Though these services were not previously employed in ICU, their suitability for use with other long-term patients will be considered as a result of the experience gained through Sandra's care.

\section{COMMUNICATION}

Ensuring good communication is a high priority when working within a large team and dealing with complex issues. This was clearly evident in the initial stage of Sandra's admission to ICU, as we were presented with communication challenges with regard to patient, family and within the health care team.

\section{Patient Communication}

The challenge for Sandra of communicating was exceptionally difficult. The only movement possible for her in the early stages of her admission was eyelid blinking. By using a blinking system, she could communicate "Yes" and "No" answers to questions. A great deal of her time and energy went into attempts to communicate, which was often a frustrating and exhausting process. To illustrate this experience from her perspective, we have included a piece written by Sandra (refer to Insert 2). 
Allied Health staff and Sandra's family worked together to devise a communication system using an alphabet board that is based on a telephone keypad (refer to Figure 1). As a result of a regimen of facial exercises and a reduction in jaw spasms, Sandra had improvement in her facial muscle movement. ${ }^{8}$ This meant that she was able to consistently mouth words and use facial expressions which, coupled with already established communication systems, has resulted in her being able to communicate more effectively. After exhaustive trials, an electronic communication device and switch (Integra Mouse ${ }^{\mathrm{TM}}$ ) has recently been introduced and Sandra is continuing to become proficient with its use.

In addition to communication regarding day-to-day issues, the health care team felt that it was important to ascertain Sandra's capacity to communicate her wishes in regard to ongoing care. Early cognitive screening was performed to determine if her basic cognition was intact (i.e. could she give reliable responses to questions and was she able to participate in therapy and decision making). Work undertaken by Schnakers et $\mathrm{al}^{16}$ in a population of patients with LIS demonstrated that these patients can recover intact cognition. They recommend systematic neuropsychological assessment to determine any cognitive deficits and contribute to improving communication with the health care team ${ }^{16}$

With regard to ongoing care Sandra is optimistic about the future and has a desire to continue rehabilitation and make the transition to a home-care environment. This is consistent with findings reported in the literature 
indicating that for patients with LIS quality of life often equates with social rather than physical interaction and that the will to live is strong. ${ }^{17}$ The realisation that Sandra felt this way also prompted a change in the way the health care team viewed the approach to Sandra's rehabilitation care.

\section{Family Communication}

Current literature demonstrates that communication with family members who have had a loved one admitted to ICU is often difficult. Families in this situation experience high levels of stress and the usual coping mechanisms are under immense strain. ${ }^{18}$ Sandra's family was no exception to this. The health care team commenced regular meetings involving as many members of the family as possible (as well as Sandra) in an attempt to keep everyone up-to-date with current issues and future plans. These meetings were held regularly to begin with and then on a needs basis, when specific issues developed or new information was received. Over time, a level of trust developed between Sandra's family and the health care team such that they could call or email with suggestions or concerns as they arose. ${ }^{19}$ Her family also instigated use of a diary to assist in communicating important days or planned events with staff. Once again, the patience and tolerance of Sandra's family has been remarkable, contributing greatly to the positive nature of the relationship.

\section{$\underline{\text { Health Care Team Communication }}$}

Current evidence with regard to rehabilitation from critical illness emphasises the importance of keeping caregivers up to date with patient specific goals 
and maintenance of activity routines. ${ }^{8} \mathrm{~A}$ large health care team such as that existing in our ICU (approximately 250 staff) presented specific challenges in relation to communication. This was particularly evident with nursing staff, the largest workforce. The goal of keeping all nursing staff informed about Sandra's condition, care requirements and future plans, was difficult to achieve. At times it was not achieved and this led to a great deal of frustration for Sandra and the staff caring for her. The strategies that were employed focused on communicating care requirements and providing general updates/progress reports.

With regard to aspects of patient care requirements, a noticeboard-style approach was taken initially. This involved members of the case management team directing her care writing instructions and displaying them on the board. Within a few weeks an entire wall was covered with instructions and it was impossible for the nurse caring for Sandra to read it all in one shift, much less follow the instructions. The next and more successful plan was to incorporate the instructions, along with rehabilitation goals into a care folder. The folder was arranged into sections which could be referred to as required.

\section{PATIENT AND FAMILY INVOLVEMENT IN CARE}

The relationship between Sandra, family and the health care team has consistently been very positive. We believe that a key contributor towards this was including Sandra and her family in care decisions and having her family involved in providing care from early in her admission. Their involvement has 
proven to be very beneficial as they are an excellent resource, being proactive in addressing Sandra's changing needs. This is consistent with Mayor's ${ }^{20}$ work in examining 'expert patients' and their families. He suggests there is great possibility of a mutually beneficial relationship between patients and families and health professionals involving shared-learning.

In Sandra's case, her family were instrumental in initiating and implementing the communication system, have taken a partnership approach to discharge planning and equipment trials, and have put much effort into investigating assistive technology for communication.

Many conversations have taken place between Sandra's family and the health care team during her admission, some simple and some very difficult. In all instances, they have been encouraged to ask questions and make comments. ${ }^{12}$ Being an intelligent and resourceful group, they have undertaken much research into Sandra's condition and treatment options, and at times have scrutinised the health care team's approach. Evidence suggests that caring for such an 'expert patient' may be a threatening experience for caregivers. ${ }^{21}$ However, we found that investing time into the relationship, being open and honest about difficulties and encouraging Sandra and her family to make suggestions has meant that this has been an enriching experience. It has encouraged us to consider new and creative ideas that we may have considered otherwise. 


\section{OUTINGS}

The concept of taking a ventilator-dependent patient away from the ICU environment is not unfamiliar. However, the decision is usually made as a result of a clinical need as opposed to 'social' need. Also it is recommended that patient transfers from ICU have a nursing and medical escort, and that equipment to manage foreseeable emergency situations accompanies the

patient at all times. ${ }^{22}$ It was obvious that the situation with Sandra required a different approach.

The plan to take Sandra out of ICU was initiated by her family who felt that it would be of great benefit for her to have some 'time-out' in a home environment. The first outing was meticulously planned and involved two ICU consultants (one driving the hospital van) and two senior ICU nurses accompanying her. Much thought went into potential problems, calculations of oxygen requirements and other possible equipment needs. The attention to detail proved to be of benefit as the first outing was uncomplicated and a great morale booster for Sandra as she got to spend time at home with her family and beloved pets.

Discussion following this trip focused on ways of minimising the ICU presence during the outing, as the aim was to remove Sandra from the ICU environment and allow her to have a break. Achieving this would mean taking less staff and less equipment, which would perhaps increase the risk. The option of going with a Registered Nurse $(R N)$ escort only and medical officer 'on-call' was suggested. A meeting was held with Sandra and her family to 
talk about this and an open discussion regarding potential risks followed. They all agreed that the benefits outweighed the risks and this decision was clearly documented and communicated with staff. The decision was also made that in the event of a life-threatening emergency an ambulance would be called, rather than the staff accompanying her being expected to manage it as they would in the ICU environment.

Further outings were undertaken with one $\mathrm{RN}$, a medical officer available to attend if necessary, and basic equipment (i.e. oxygen, manual resuscitation bag, suction equipment). The $\mathrm{RN}$ who was to go with Sandra was allocated ahead of time and informed of the patient/family discussion surrounding outings. Some of the places that Sandra has been to while an inpatient in ICU include an international cricket match, the cinema, the theatre, music concerts, shopping trips, family birthday parties and weddings and sometimes just time at home with family (see Figure 3). She has also been able to leave the unit to attend appointments with her solicitor, optometrist and for acupuncture treatment.

The mode of transportation for outings has changed over time. Initially we used a hospital-owned van designed for transportation of wheelchair bound patients. However as this meant that we needed to have an additional staff member as driver it was not a feasible long-term option. A commercial wheelchair capable taxi has been used since then as well as the train, which is Sandra's preferred mode of transport due to its comfort. 
Initially, some degree of unease was experienced by nursing staff, with the idea of Sandra leaving the security of the ICU environment. There was even a strongly negative reaction from some of the senior nursing staff who were uncertain about legal responsibility. Perceptions changed over time however as they realised that the risks had been discussed in-depth with Sandra and her family. After some very successful and enjoyable outings staff became more comfortable, and even requested to care for Sandra in order to accompany her on outings. At one point a limit had to be placed on outings as there were three planned in one week, leaving insufficient time for rehabilitation therapy!

\section{MODEL OF NURSING CARE}

The impact of having a long term patient in the ICU has been multifaceted. It has affected the case management team as well as those involved in providing fundamental care. With a large number of RNs on our roster the challenge of maintaining continuity of care was immense. Initially a primary care group (RNs who had volunteered to care for Sandra on a regular basis) was established. While this worked well it could not be maintained as there were too few volunteers and many of those who did volunteer withdrew as they found it 'too stressful'.

Much has been documented about the causes of stress experienced by critical care nurses, for example communication difficulties, inadequate resources or staffing, exposure to family distress and exposure to patient suffering. ${ }^{23}$ The stress of caring for a chronic or long-term critically ill patient 
has also been recognised. ${ }^{5}$ As previously mentioned, there may also be stress for caregivers, particularly junior staff, when confronted with an 'expert patient' and family. ${ }^{21}$

Additionally there appears to be a degree of stress experienced by critical care nurses in caring for a long-term, non-acute patient. This could perhaps be related to 'task identity' or assumptions around the kind of work critical care nurses should or should not be doing. ${ }^{24}$

Regardless of the source of stress in this particular case, we found that the lack of a team of primary caregivers meant that continuity of care for Sandra was impacted. Within a few months it became apparent that we needed to trial a new model of nursing care. The new model was based on that used to care for ventilator-dependent people in the community setting. It involves Assistants in Nursing (AINs) providing fundamental care on a twenty-four hour basis, with indirect supervision provided by senior ICU RN. ${ }^{25}$

Like all proposed changes to staffing in a large organisation, this required formulation of a business case outlining the benefits, risks and cost (or cost saving) of such a model. Once approval was gained we were able to commence implementation. Although it is too early to determine the impact that this model has had on the ICU, it has certainly been met with great enthusiasm by Sandra and her family as well as the AINs employed. Additionally, the cost savings associated with this model allowed for employment of a part-time Clinical Nurse Case Manager to oversee AIN 
training and discharge planning processes, as well as purchase of specialised rehabilitation equipment (i.e. long-term ventilator, shower/commode chair).

\section{FUTURE CONSIDERATIONS}

Planning for a transition to home-based care is the focus of our current activities. Associated with this is the need to consider plans for Sandra's management post-discharge. Specific considerations include ongoing care, equipment management, follow-up requirements and plans for hospital readmission should Sandra become unwell. Essentially, we need to consider that even in home-based care, Sandra will remain an ICU patient (according to current health district policy) and we therefore need to remember this in future planning for the ICU.

Another area that needs to be taken into account is the decision surrounding

limitation of treatment in the event of deterioration in Sandra's condition. ${ }^{26}$ The health care team felt that it was important to discuss and document her wishes quite early on to ensure that, regardless of the staff involved at the time, her decision would be supported. While these very difficult issues have been discussed openly with Sandra and her family, the impact of limiting therapy would be significant, given the established relationship between staff and patient/family.

\section{SUMMARY}

The desire of the team in putting this publication together was to provide an overview of our experience in the hope that it might be helpful to others who 
find themselves in similar circumstances given that existing literature is scant. While many issues have been covered, the key elements in promoting success in caring for a permanent-resident in ICU are described in the following suggestions:

- Establish and maintain an open and honest relationship with the patient and family, encouraging questions, discussion of issues and suggestion of ideas

- Begin regular multi-disciplinary case meetings as early as possible in the patient's admission to promote teamwork, clarify direction and provide support for team members

- Consider new ideas and methods, weighing the benefits to the patient against the risks

- Recognise the importance of communication with the broader health care team regarding patient plans, care instructions and also the type of care (i.e. rehabilitation rather than acute)

Implementation of these principles has proved effective in developing a model of care that meets the needs of Sandra as a permanent resident in our ICU. Although the process has been challenging for everyone involved, there have been many benefits gained.

\section{ACKNOWLEDGMENT}

The Authors would like to acknowledge the contribution of Sandra and her family in the production of this article. They have willingly provided their 
consent, support and collaboration and have approved the content in its final form. 


\section{INSERTS:}

\section{Insert 1: Clinical Scenario}

A previously well, 32 year old female, was admitted to hospital for treatment of streptococcal meningitis likely secondary to an ear infection. This was then complicated by tonsillar herniation and upper spinal cord infarction following a lumbar puncture.

Initial management included an extraventricular drain and a posterior fossa and upper cervical decompression. Over the ensuing weeks she had multiple courses of antibiotics to treat the infection, but was unfortunately left with a very significant upper spinal cord / brain stem infarction. Her condition has been described as Locked-in Syndrome (LIS). LIS is most commonly defined as quadriplegia and anarthria (inability to speak), with preservation of consciousness. $^{12}$

Sandra is totally dependant on mechanical ventilation and requires full assistance for all her daily needs. She has a Tracheostomy to facilitate ventilation and has had a suprapubic catheter and gastrostomy feeding tube inserted. She has experienced difficulties with pain issues, recurrent muscle spasm and recurrent infections. Specialist opinions have been obtained from neurologists, neurosurgeons and spinal rehabilitation specialists all of whom concur that unfortunately her severe disability is likely to be permanent. 


\section{Insert 2: The Patient's Perspective: "I am not stupid!”}

My name is Sandra. I have been here [Intensive Care] since September $3^{\text {rd }}$ 2007. I have Locked-in-Syndrome and the first sentence I spelled out when able to was "I'm not stupid!" I ended up in ICU after complications with a lumbar puncture and have been here ever since. It is not the right place for me as ICU is designed for short term patients who need intensive care. Unfortunately my treatment does not allow me to be transferred to any other ward in the hospital.

The ICU staff have been wonderful even though I am not the type of patient they are used to caring for. They have been very accommodating for me and my family. Because of the hustle and bustle of the central ICU area I was moved after several months into an isolation room. It has become my home and allowed me to be removed from the day to day activity of the ICU and to start getting into a daily routine and to start my journey to going home.

The biggest problem living in ICU is that I would have three different nurses every day and the rotation of the nursing staff was such that I may not see a particular nurse for another month. Every shift I would need to go through the same routine with the nurses who needed to reacquaint themselves with the stage that I was at, with each of them having their own way of doing things. The hardest thing was communication. Some of the nursing staff did not know the communication system. I even had one nurse read through the entire alphabet to me. It takes a long time to spell out a word this way, let alone a whole sentence. 
It was this problem that caused the ICU management to change their mode of operation. They set up Bed 29 and allowed my family to decorate and make it more homely and inviting. They also employed a case manager and six personal carers (Assistants in Nursing, AIN). This provided a consistency of care lacking previously.

I have come so far since my admission especially in the last two months. I'm not sure if this is because of the AIN's or time or both. When I got here I was little more than a vegetable, with no movement except the occasional blink and the memory of a goldfish. Now I am back to normal, excepting the fact I have no sensation below the chin, and am fully ventilated. I have started eating once a week and hope to start talking soon.

I would like to thank Mum, Andy, Dad, Sharon, Fiona, Danielle, Cecille, Alison, Emily, Kelly, Catherine, the AIN's and Beth, all of whom I could not do without. 


\section{REFERENCES}

1. Princess Alexandra Hospital Intensive Care Cerner-APACHE III Database. Accessed 1st August 2008

2. New P. Non-traumatic spinal cord injury: what is the ideal setting for rehabilitation? Australian Health Review 2006;30(3):353-361.

3. MacIntyre NR, Epstein SK, Carson S, Scheinhorn D, Christopher K, Muldoon S. Management of patients requiring prolonged mechanical ventilation: report of a NAMDRC consensus conference. Chest 2005;128(6):3937-54

4. Scheinhorn DJ, Hassenpflug MS, Votto JJ. Chao DC, Epstein SK, Doig GS, Knight EB, Petrak RA. Post-ICU mechanical ventilation at 23 longterm care hospitals: a multicenter outcomes study. Chest 2007;31(1):8593.

5. Carasa M, Nespoli G. Nursing the chronically critically ill patient. Critical Care Clinics 2002;18(3):493-507.

6. Rudy EB, Daly BJ, Douglas S, Montenegro HD, Song R, Dyer MA. Patient outcomes for the chronically critically ill: special care unit versus intensive care unit. Nursing Research 1995;44(6):324-31.

7. Rahman A, Dedhia H, Parker JE, Teba L, Vasudevan CP. Prolonged mechanical ventilation: are your ventilator patients ready to be cared for outside ICU? West Virginia Medical Journal 2007;103(5):24-6.

8. Casanova E, Lazzari R, Lotta S, Mauzzucchi A. Locked-in syndrome: improvement in the prognosis after an early intensive multidisciplinary rehabilitation. Archives of Physical Medicine and Rehabilitation 2003;84:862-867. 
9. Janoff-Bulman R. Shattered Assumptions 2002 The Free Press: New York.

10. Criner G, Travaline J. Transitional respiratory care and rehabilitation. Current Opinion in Critical Care 1999;5(1):81

11. Thomas D, Kreizman I, Melchiorre P, Ragnarsson K. Rehabilitation of the patient with chronic critical illness. Critical Care Clinics 2002;18:695-715.

12. Davidson J, Powers K, Hedayat K, Tieszen M, Kon A, Shepard E, Spuhler V, Todres D, Levy M, Barr J, Ghandi R, Hirsch G, Armstrong D. Clinical practice guidelines for support of the family in the patient-centred intensive care unit: American College of Critical Care Medicine Task Force 2004-2005. Critical Care Medicine 2007;35(2):605-622.

13. Eskildsen M. Long-term acute care: a review of the literature. Journal of American Geriatric Society 2007;55:775-779.

14. Giuliano K, Bloniasz E, Bell J. Implementation of a pet visitation program in critical care. Critical Care Nurse 1999;19(3): 43-50.

15. Keegan L. Therapies to reduce stress and anxiety. Critical Care Nursing Clinics of North America 2003;15(3):321-327.

16. Schnakers C, Majerus S, Goldman S, Boly M, Van Eeckhout P, Gay S, Pellas F, Bartsch V, Peigneux P, Moonen G, Laureys S. Cognitive function in the locked-in syndrome. Journal of Neurology 2008;255(3):323-330.

17. Doble J, Haig A, Anderson C, Katz R. Impairment, activity, participation, life satisfaction and survival in persons with locked-in syndrome for over a decade: follow-up on a previously reported cohort. Journal of Head Trauma Rehabilitation 2003;18(5):435-444. 
18. Kirchhoff K, Song M, Kehl K. Caring for the family of the critically ill patient. Critical Care Clinics 2004;20:453-466.

19. Paul F, Rattray J. Short and long-term impact of critical illness on relatives: literature review. Journal of Advanced Nursing 2008;62(3):276292.

20. Mayor V. Long-term conditions. 3: Being an expert patient. British Journal of Community Nursing. 2006;11(2):59-63.

21. Wilson P, Kendall S, Brooks F. Nurses' response to expert patients: The rhetoric and reality of self-management in long-term conditions: A grounded theory study. International Journal of Nursing Studies 2006;43:803-818.

22. Papson J, Russell K, Taylor D. Unexpected events during the intrahospital transport of critically ill patients. Academic Emergency Medicine $2007 ; 14(6): 574-577$.

23. Levy M. Caring for the caregiver, Critical Care Clinics 2004;20:541-547.

24. Stechmiller J, Yarandi H, Job satisfaction among critical care nurses. American Journal of Critical Care 1992;1(3):37-44.

25. Queensland Nursing Council Setting the Standards Framework Information Sheet - 'Delegation and clinically focused supervision: unlicensed health care worker'. [Online resource - available at http://www.qnc.qld.gov.au/publications Accessed 4th August 2008] 26. Curtis JR. Communicating about end-of-life care with patients and families in the intensive care unit. Critical Care Clinics 2004;20:363-380. 